\title{
EDITORIAL
}

\section{LA ENSEÑANZA DE LAS CIENCIAS NATURALES Y LA EDUCACIÓN AMBIENTAL EN LA ESCUELA: REALIDADES Y DESAFÍOS}

\author{
"Quien conozca sólo un punto de vista o una forma de ver \\ las cosas no cree que otro baya estado nunca en su lugar ni \\ que otro venga después; ni duda, ni bace pruebas" \\ (Ernst Mach,1911)
}

Hoy se reconoce la importancia de la formación en Ciencias en la escuela básica y media, pues la influencia de los asuntos científicos y tecnológicos en la cotidianidad de cualquier individuo es evidente y creciente. Dicha realidad denota la necesidad de fortalecer espacios educativos que, de la mano de las diversas tendencias pedagógicas y didácticas, promuevan la formación de ciudadanos que se interesen por debatir las cuestiones socio-científicas de manera individual y colectiva. La consolidación de tales espacios demanda la formación de docentes que se comprometan con el desarrollo de ejercicios de autorreflexión en torno al quehacer y la práctica pedagógica, de forma tal que se asuma la necesidad de contribuir al estudio y análisis de la situación de los aprendizajes de los niños, niñas y jóvenes, reconociendo las fortalezas y oportunidades del proceso, lo que sin duda contribuirá a pensar en nuevas y diferentes formas de plantear la enseñanza de las Ciencias.

En las últimas tres décadas la Didáctica de las Ciencias se ha interesado en transformar la enseñanza de éstas, con el fin de alcanzar un aprendizaje significativo a partir del redescubrimiento del conocimiento y del desarrollo de actividades que procuren superar las visiones reduccionistas de la metodología científica privilegiadas en la escuela y diversos espacios; visiones que suelen desconocer que la producción de conocimiento científico es y ha sido una actividad intelectual que requiere de la interacción social. Así entonces, la enseñanza de las Ciencias ha de pretender que el 
cambio conceptual en los individuos esté mediado por la confrontación y discusión de alternativas diversas, a través del conocimiento de la historia y naturaleza de la Ciencia, robusteciendo el desarrollo de la iniciativa y la creatividad y dejando de lado la mera transmisión de visiones y conocimientos a través de experiencias que muestran "verdades absolutas" y que no dan lugar a la pregunta, la especulación y la reflexión.

Esto sin duda contribuirá a fortalecer una sociedad más equitativa, democrática y justa, pues el acceso al conocimiento científico y a una cultura científica como pilar de una formación ciudadana que posibilitará la toma de decisiones responsables e informadas, habitualmente es desigual en la actualidad. La enseñanza de las Ciencias Naturales en el contexto de la escuela básica y media suele situarse en tres grandes temáticas: 'Seres Vivos y Salud', 'Tierra y Ambiente' y 'Materia y Energía'. Los estándares de Competencias Básicas en Colombia abordan dichas temáticas desde el entorno vivo, el entorno físico y las relaciones Ciencia, Tecnología y Sociedad, y son múltiples los proyectos y acciones que han procurado involucrar la innovación y el cambio en el diseño de contenidos, materiales y metodologías que, de una u otra forma, contribuyan a garantizar un proceso que procure el desarrollo de habilidades científicas y la comprensión de los fenómenos de la naturaleza desde las nuevas concepciones de Ciencia y, por lo tanto, de la educación científica.

Este número de la revista Praxis $\mathcal{E}$ Saber está dedicado a analizar, desde miradas diversas, las necesarias y antes citadas reflexiones. Así, el lector tendrá la oportunidad de deleitarse con los aportes hechos por los autores y que son producto del estudio de realidades educativas y proyectos de investigación que proporcionarán al docente en ejercicio elementos que enriquecerán su cotidianidad en el aula.

Así, en primer lugar, el lector se encontrará con un artículo de investigación escrito por la invitada internacional, la Dra. Melina Furman — quien es reconocida en el contexto latinoamericano por liderar la Enseñanza Basada en la Indagación en la escuela básica- el cual invita a los lectores a cuestionar el tipo de Ciencia que se enseña en escuelas de contextos de pobreza y presenta los resultados de un proyecto de investigación que analizó los desempeños en competencias científicas de alumnos del nivel primario ( $4 .^{\circ}$ y $6 .^{\circ}$ grado), tomando una muestra de 3.000 niños de escuelas de seis provincias argentinas y que forman parte del Programa 
Escuelas del Bicentenario. La autora revela su preocupación porque los resultados señalan que un alto porcentaje de los niños no domina las competencias evaluadas, especialmente aquellas más complejas. El trabajo aporta nuevas evidencias sobre la urgente necesidad de un replanteo de la enseñanza de las Ciencias y sobre el rol que el docente ha de asumir para emprender acciones de mejora.

Luego en el artículo intitulado Estudio de caso: una estrategia para la Enseñanza de la Educación Ambiental, la profesora Leomary Niño Barajas hace un recuento sobre los fines, principios y objetivos de la Educación Ambiental y de la importancia que ha de cobrar en la escuela, pues como lo señala la autora, ha de "favorecer la formación de sujetos sensibles por el medio ambiente, con capacidad para construir conocimientos y adoptar posiciones críticas y reflexivas que les permita la toma de decisiones frente a problemáticas del entorno". En el artículo se manifiesta la relevancia que ha de tener en la escuela la relación que históricamente se ha establecido entre la enseñanza de las Ciencias Naturales y la Educación Ambiental, y cómo la aplicación del estudio de caso como estrategia didáctica favorece el desarrollo del carácter epistemológico y metacognitivo de la alfabetización científica, al permitir que estas disciplinas puedan entrecruzarse, complementarse, y contribuir a la reflexión sistémica sobre la práctica social y educativa.

Continuando con la temática abordada, el profesor Gustavo Adolfo Flórez Restrepo, presenta los resultados de un ejercicio de reflexión que dio origen a la formulación y ejecución del proyecto Comunidad de Aprendizaje para la Educación y la Acción Ambiental, propuesta que se adelanta en doce municipios de las provincias de Sugamuxi y Tundama del departamento de Boyacá con el acompañamiento del sector privado. El artículo presenta a la comunidad educativa las cuestiones en torno a las cuales gira la incursión de la Educación Ambiental en Colombia, planteando la necesidad de generar escenarios de debate que permitan evaluar, rediseñar e innovar las estrategias que hasta ahora se han implementado y que deben procurar la interacción e integración de actores sociales diversos, lo que sin duda posibilitará la comprensión de la dimensión ambiental. La 'comunidad de aprendizaje' se plantea entonces como la posibilidad de propiciar escenarios para el diálogo, la discusión y la reflexión colectiva, espacios que permitirán generar la construcción social del saber ambiental. 
La necesidad de que la escuela establezca un diálogo abierto con la sociedad en torno a los avances científicos y tecnológicos, se aborda en el artículo Actitudes hacia las relaciones CTS: estudio con docentes universitarios de Ciencias Naturales, escrito por las profesoras Inés Andrea Sanabria y María Mercedes Callejas. Este artículo, producto de un proyecto de investigación realizado en el marco del Proyecto Iberoamericano de Evaluación de Actitudes Relacionadas con la Ciencia, la Tecnología y la Sociedad (PIEARCTS), presenta la identificación de las actitudes hacia las relaciones CTS de docentes de la Licenciatura en Ciencias Naturales y Educación Ambiental de la Universidad Pedagógica y Tecnológica de Colombia, a partir de la aplicación del Cuestionario de Opiniones sobre Ciencia, Tecnología y Sociedad (COCTS). Los resultados de dicho estudio revelan la necesidad de planificar estrategias que contribuyan a mitigar las actitudes negativas y a fortalecer las actitudes positivas hacia algunas de las cuestiones planteadas; así la importancia de sus aportes radica en el hecho de que se cuestionan algunos aspectos de la formación de docentes en las Facultades de Educación y Programas de Licenciatura, invitando a unos y a otros a revisar las actividades que pueden y deben desarrollarse en pro de la alfabetización científica y de la consolidación de una cultura de la ciencia y la tecnología.

Siguiendo la reflexión en torno a la educación superior, la profesora Sara Raquel Silva Ortiz presenta la sistematización (propuesta derivada de las metodologías propias de la investigación científica), como un proceso que ofrece la oportunidad de resignificar de manera concertada y contextualizada la experiencia del docente, contribuyendo así a transformar las prácticas y las realidades educativas. Este artículo de reflexión revisa los fundamentos teóricos y epistemológicos en torno a la sistematización de las prácticas, proyectando además una propuesta de sistematización de una experiencia formativa relacionada con la enseñanza de la Anatomía en mediación con una alternativa didáctica, el Aprendizaje Basado en Problemas (ABP). El lector tendrá la oportunidad de reconocer la forma como la sistematización ha entrado a la universidad, guiada por los fundamentos de la educación de adultos y de la educación popular para generar una reflexión y una práctica que permitan posicionar la sistematización como una opción investigativa para la generación de saber, producto de un ejercicio de diálogo de saberes y negociación cultural.

Finalmente y con el propósito de abrir espacios de diálogo, este número de la revista presenta tres artículos que si bien no abordan puntualmente 
el tema de enseñanza de las Ciencias, contribuyen significativamente a contar con elementos de reflexión que enriquecen las discusiones mencionadas. El primero aborda una temática que suele preocupar y cuestionar al docente y que ha sido considerada un elemento esencial de transformación si realmente se quieren obtener mejoras en la enseñanza: la evaluación. El profesor Julio Fernando Acosta y la estudiante Alexandra Cifuentes presentan una revisión teórico-conceptual sobre la condición motivacional en la evaluación educativa. Se presenta entonces un análisis de las formas como se evalúan los aprendizajes y el papel que desempeñan los estudiantes, el maestro y la motivación.

El segundo artículo, escrito por el profesor Juan Guillermo Díaz Berna, aborda desde una perspectiva histórica una problemática a la que se enfrenta el hombre contemporáneo y que se expresa en una pregunta: ¿Es la Sociedad de la Información una Sociedad del Conocimiento (SIC)? El análisis evidencia la importancia del trabajo en la educación y la pedagogía en el siglo XXI cuyas consecuencias afectan al conocimiento, por lo menos, en tres momentos: uno genealógico, que es donde se configuran los orígenes de la reflexión; otro, mostrando las novedades de la sociedad porque está muy influenciada por la tecnología capitalista globalizada y, por último, mostrando los cambios en la sociedad. La tesis central explicará qué tiene de nuevo la SIC respecto a otros tipos de sociedad y cuáles son sus peculiaridades que la hacen tan especial, singular y diferente de las sociedades anteriores, para luego pasar a describir cuáles son los cambios que provoca en la manera de entender las relaciones sociales, en la organización política y económica.

El artículo La Educación Filosófica como experiencia y posibilidad, escrito por la docente Liliana Andrea Mariño, estudia la importancia del desarrollo de la actitud filosófica en estudiantes y docentes como posibilidad, condición y experiencia de la educación en los momentos actuales. Procede metodológicamente describiendo y aclarando los enunciados y prácticas que giran alrededor de la actitud filosófica y su interacción con los procesos educativos y pedagógicos. Este artículo cierra el número cinco de la revista, recogiendo muchas de las reflexiones planteadas por todos los autores, pues se propone la Educación Filosófica como la posibilidad de hacer del aula un espacio propicio para la investigación, partiendo de las cuestiones o inquietudes de los estudiantes, en el que el docente recobra un papel protagónico como el ser que los incentiva a buscar nuevas experiencias que les permita construir y 
encontrar respuestas a sus interrogantes para vivir un encuentro, aventura y experiencia con el conocimiento.

La línea de Investigación en Innovación en Didáctica de las Ciencias Naturales y la Educación Ambiental de la Maestría en Educación, apropió este espacio de construcción colectiva como la posibilidad de repensar la enseñanza de las Ciencias Naturales, partiendo de los invaluables aportes de los docentes. Este es un número que aborda temáticas diversas y coincidentes que esperan propiciar en el lector el interés por la investigación en situaciones que una vez estudiadas contribuirán a fortalecer y mejorar las prácticas en el aula y que, sin duda, apuntarán a lograr una mejor educación para nuestros niños y jóvenes.

Gloria Leonor Gutiérrez Gómez 